\title{
LA UNIVERSIDAD NACIONAL DE LA PLATA COMO OBJETO DE CONTROL ESPACIAL-POBLACIONAL DURANTE LA ÚLTIMA DICTADURA MILITAR ARGENTINA
}

\author{
ALEX COLMAN (UBA - ANPCyT) \\ Instituto de Lingüística, Universidad de Buenos Aires \\ alexdcolman@gmail.com
}

\begin{abstract}
Resumen:
En este trabajo estudio la vigilancia ejercida por el Estado sobre la Universidad Nacional de La Plata durante la última dictadura militar argentina (1976-1983) como parte de una política de control espacial-poblacional. El análisis se centra en dos tomos de un legajo referente a dicha universidad, encontrado en el archivo de la Dirección de Inteligencia de la Policía de la Provincia de Buenos Aires (DIPBA). Específicamente, examino las políticas educativas y espaciales enunciadas en estas producciones, así como la construcción mitologemática de la amenaza. Mantengo que es posible considerar el control espacial-poblacional del campus universitario como un discurso biopolítico, donde la noción de multitud asume un carácter anfibológico que oscila entre un polo positivo y otro negativo. Esta ambigüedad se vincula a una concepción de la (in)seguridad como supervivencia respecto de una vida como amenaza anulada o latente.
\end{abstract}

\section{Palabras clave:}

Espacio, población, dictadura militar, DIPBA, Universidad Nacional de La Plata

\begin{abstract}
:
In this paper I study the surveillance exercised by the State over the National University of La Plata during the last Argentine military dictatorship (1976-1983) as part of a space-population control policy. The analysis focuses on two volumes of a file referring to that university, found in the archive of the Intelligence Directorate of the Buenos Aires Provincial Police (DIPBA). In particular, I examine the educational and spatial policies enunciated in these productions, as well as the mythologematic construction of the threat. I maintain that it is possible to consider the space-population control of the university campus as a biopolitical discourse, where the notion of multitude assumes an amphibological character that oscillates between a positive and a negative pole. This ambiguity is linked to a conception of (in)security that considers it as survival with respect to a life as a canceled or latent threat.
\end{abstract}

\section{Keywords:}

Space, population, militar dictatorship, DIPBA, National University of La Plata 


\title{
LA UNIVERSIDAD NACIONAL DE LA PLATA COMO OBJETO DE CONTROL ESPACIAL-POBLACIONAL DURANTE LA ÚLTIMA DICTADURA MILITAR ARGENTINA
}

\author{
ALEX COLMAN (UBA - ANPCy'T) \\ Instituto de Lingüística, Universidad de Buenos Aires \\ alexdcolman@gmail.com
}

La Dirección de Inteligencia de la Policía de la Provincia de Buenos Aires (DIPBA) fue un servicio de inteligencia dependiente de la Policía Bonaerense que funcionó entre 1956 y 1998, año en el que fue cerrada por Resolución número 9 del Ministerio de Seguridad y Justicia de la Provincia de Buenos Aires. Su archivo fue cedido a la Comisión Provincial por la Memoria en el año 2000, y abierto a la consulta pública en 2003, siendo utilizado en procesos judiciales e investigaciones sobre cuestiones diversas.

Según los distintos períodos históricos, la DIPBA informaba a la cúpula política sobre los diversos acontecimientos, acciones y modalidades de organización protagonizados por los sectores que investigaba. Durante la última dictadura militar argentina (1976-1983), una de las tareas de la DIPBA fue vigilar sistemáticamente y promover modalidades específicas para el control de la vida universitaria en el área de su jurisdicción. Los tomos VII y VIII del Legajo 20 encontrado en su archivo -enteramente abocado a la Universidad Nacional de La Plata (UNLP)dan cuenta de una política de control espacial-poblacional ${ }^{1}$ que transformó profundamente la vida universitaria de dicha localidad durante esos años.

Desde una aproximación que combina una perspectiva antropológica y un enfoque arraigado en los estudios sobre biopolítica, analizo las políticas educativas y espaciales enunciadas en las producciones de ambos tomos, así como la construcción mitologemática de la amenaza. Las articulaciones entre concepciones de la seguridad, la educación, la salud y la economía, emergentes en el corpus como despliegues dóxicos, apuntan a considerar el control espacialpoblacional del campus universitario como un discurso biopolítico, donde la noción de multitud asume un carácter anfibológico que oscila entre un polo positivo y otro negativo. Concluyo que esta ambigüedad se encuentra vinculada a una concepción de la (in)seguridad como supervivencia respecto de una vida como amenaza anulada o latente. ${ }^{2}$

\section{El espacio y la población}

El espacio puede ser pensado como "un producto que se consume, que se utiliza, pero que no es como los demás objetos producidos, ya que él mismo interviene en la producción". ${ }^{3}$ Si cada sociedad produce su espacio, a su vez, este se encuentra atravesado por determinadas concepciones histórico-políticas, cuya inscripción en el mismo puede revelar proyectos

1 Cf. Cavalletti, Andrea, Mitología de la seguridad. La ciudad biopolitica, Buenos Aires, Adriana Hidalgo, 2010.

2 Esta investigación se enmarca en los proyectos UBACyT 20020150100238 y PICT 2015 3712, dirigidos por la Dra. María Alejandra Vitale, y ha sido financiada por una beca estímulo UBACyT y una beca CIN.

3 Martínez Lorea, Ion, "Henri Lefebvre y los espacios de lo posible", en Lefebvre, Henri, La producción del espacio, Madrid, Capitán Swing, 2013, p. 14. 


\section{estratégicos.}

Por ejemplo, la subjetividad implica un modo de existencia en el espacio en el que subyace una concepción de los límites entre interioridad y exterioridad, y toda una definición (política) del espacio. Esta forma de inscripción de la espacialidad ilumina un ejercicio de poder mediante el sujeto, así como los modos en que una determinada representación del espacio se constituye en práctica espacial y viceversa.

Según Henri Lefebvre, el espacio del capitalismo - "de la modernidad"- posee características definidas: homogeneidad-fragmentación-jerarquización. ${ }^{4}$ Estos caracteres, producto de tendencias discordantes, son precisamente aquellos que definen la figura general de la noción moderna de población.

De hecho, Andrea Cavalletti ha definido el concepto de población -en su sentido biopolíticocomo "un concepto espacial preciso, puesto que biopouvoir quizás en el fondo significa un poder coesencial al concepto espacial de población". 5 A una instancia homogénea, que puede corresponderse con la noción de especie como tipo de colectividad natural, ${ }^{6}$ se le aplican una o más cesuras (fragmentación), cuyos productos, a su vez, son jerarquizados -por ejemplo, mediante las ideologías de supremacía racial- y puestos en contradicción recíproca.

El paradigma contemporáneo de la seguridad aplica estas rupturas y contradicciones en una espacialidad propia, que actúa "desde la escala más amplia hasta la de los cuerpos, desde el nivel estadístico o [...] 'regulativo' hasta el 'disciplinario', y de este al otro". 7 De esta manera, mediante un doble dispositivo de exclusión e individualización, ${ }^{8}$ que se funda en la clasificación dicotómica (ente peligroso / inofensivo) y en la heteroatribución coercitiva de caracteres que faculta una vigilancia metódica en el espacio urbano, el discurso de la seguridad autoriza la proyección de una negatividad aparente a nivel poblacional a partir de rasgos corporales y de carácter, así como la proyección de una peligrosidad a nivel corporal a partir de regularidades estadísticas.

Población y no-población son representaciones consustanciales al espacio urbano en la modernidad. Según Michel Foucault, durante el siglo XVIII se produjo una transformación del espacio de la ciudad, la cual se tornó polifuncional. Como expresión de la adopción de la perspectiva poblacional, a partir de este momento la ciudad se regirá mediante la gestión de probabilidades y en función de un ordenamiento que intentará "maximizar los elementos positivos, que se circule lo mejor posible, y minimizar, al contrario, los aspectos riesgosos e inconvenientes como el robo, las enfermedades, sin desconocer, por supuesto, que jamás se los suprimirá del todo".?

A su vez, Paolo Virno ha intentado ligar la noción de biopolítica -entendida como regulación de la población mediante un poder que impacta a nivel de la vida y de los procesos biológicos- al concepto de fuerza de trabajo, que encarna la categoría de "potencia" (dynamis) y que a su vez puede ser comprada o vendida como cualquier otra mercancía. Según el pensador italiano, estas "características paradójicas de la fuerza de trabajo [...] son la premisa de la biopolítica":

"Al capitalista le interesa la vida del obrero, su cuerpo, sólo por un motivo indirecto: este cuerpo, esta vida, son aquello que contiene la facultad, la potencia, la dynamis. El cuerpo

\footnotetext{
4 Lefebvre, Henri, La producción del espacio, Madrid, Capitán Swing, 2013, p. 58.

5 Cavalletti, Andrea, Mitología de la seguridad..., op. cit., p. 18.

6 Cf. Foucault, Michel, Defender la sociedad. Curso en el Collège de France (1975-1976), Buenos Aires, Fondo de Cultura Económica, 2000.

7 Cavalletti, Andrea, Mitología de la seguridad..., op. cit., p. 18.

8 Cf. Foucault, Michel, Vigilary castigar, Buenos Aires, Siglo XXI, 2014.

9 Foucault, Michel, Seguridad, territorio y población. Curso en el Collège de France (1977-1978), Buenos Aires, Fondo de Cultura Económica, 2009, p. 39.
} 
viviente se convierte en objeto a gobernar no tanto por su valor intrínseco, sino porque es el sustrato de la única cosa que verdaderamente importa: la fuerza de trabajo como suma de las más diversas facultades humanas -potencia de hablar, de pensar, de recordar, de actuar, etcétera". ${ }^{10}$

Si la población es aquella multiplicidad cuyos procesos biológicos son gestionados a nivel estadístico con el objetivo último de extraer fuerza de trabajo, entonces las oscilaciones en la demanda de esta última van a configurar, históricamente, la extensión y límites de la primera. De ahí que la extensión de la no-población como negatividad aparente y virtual amenaza ${ }^{11}$ estará condicionada, también, por las oscilaciones en la compra-venta de fuerza trabajo, y, por lo tanto, por la existencia, en la ciudad, de sectores en posición de inclusión / exclusión respecto de las condiciones de trabajo (y de vida) consideradas normales. La conformación de la pobreza $-\mathrm{o}$ la criminalidad- y de la subversión -o el terrorismo- como objetos (discursivos) de vigilancia y de control parecen ser aspectos de un mismo modelo, mitologemas en los que se ampara y construye el gobierno moderno.

La recreación constante de una amenaza hacia la ciudadanía -como polo poblacional positivo-, y el dinamismo con el que ambos polos -negativo y positivo- oscilan según el contexto histórico, económico y social, muestran la ambigüedad intrínseca a la noción de multitud. Esta noción, en el transcurso del siglo XVIII, sufrió una cesura entre "el nivel pertinente para la acción económico política del gobierno, el nivel de la población, y otro nivel, el de la serie, la multiplicidad de individuos", ${ }^{12}$ que sólo será pertinente en vistas del gobierno empírico de la primera. Sin embargo, tal vez fue la generalización práctica de la noción de emancipación -configurada como proyecto histórico incompleto- $-{ }^{13}$ lo que permitió que reaparezca una ambigüedad fundamental ya presente en la filosofía política del siglo XVII, según la cual las nociones de pueblo y poblaciónescindidas en el discurso biopolítico- volvieron a confundirse.

\section{El control espacial-poblacional de la Universidad Nacional de La Plata}

La antedicha oscilación puede corroborarse en nuestro corpus. Como se verá, las potencialidades de irrupción de la multitud son incesantemente anticipadas por los agentes de la DIPBA, configurando para 1979 una sensación de relativa e insegura tranquilidad. El tono de algunas de las producciones de este año y de 1980 hacen pensar en la calma que precede a la tormenta, pero también es consecuencia de una acción ya ejecutada: la anulación de los principales centros de contagio y focos infecciosos de la subversión. Veamos entonces cómo se instancia esta transformación del espacio universitario mediante ciertas políticas educativas y espaciales del gobierno dictatorial que son enunciadas o referenciadas en el material de la DIPBA.

\section{La transformación del espacio universitario}

Durante la dictadura se implementaron políticas que tendieron a transformar cualitativamente el espacio universitario. Los principales aspectos de este control tuvieron que ver con la transformación arquitectónica, la regulación del espacio interno y externo de la Universidad, el control del acceso y del ingreso, y también con una política de despoblación mediante la anulación de cuerpos y espacios.

10 Virno, Paolo, Gramática de la multitud. Para un análisis de las formas de vida contemporáneas, Madrid, traficantes de sueños, 2003, p. 85.

11 Cf. Cavalletti, Andrea, Mitología de la seguridad..., op. cit.

12 Foucault, Michel, Seguridad, territorio y población..., op. cit., p. 63.

13 Koselleck, Reinhart, Historias de conceptos. Estudios sobre semántica y pragmática del lenguaje político y social, Madrid, Trotta, 2012. 
En una temprana elaboración sobre los materiales del archivo de la DIPBA, Magdalena Lanteri et al. analizaron los modos en que el Comedor Universitario, como espacio físico y geográfico de vigilancia, fue percibido por dicho servicio de inteligencia:

"la DIPBA pensó el CU [Comedor Universitario] siempre como un depósito vivo de insurgencia: bastión político y de disputa propagandística, significó el lugar dónde. Donde se movilizaba el factor político, sindical, universitario que había que perseguir, fichar, estigmatizar, reidentificar, relevar. Donde irrumpía el factor sedicioso en vivo y en directo. Donde, en definitiva, se regeneraba el germen: el CU, como otros espacios físicos, era en los ojos policiales un nicho infeccioso y de reproducción de elementos disolventes". ${ }^{14}$

Ahora bien, en 1977 el Comedor Universitario fue definitivamente clausurado; en el folio 18 de nuestro corpus, un informe relata una reunión del Rector interventor Guillermo Gallo con el Diario El Día en la que aquel se refirió "al traslado de una facultad, adelantando que se había dictado la resolución pertinente con el fin de que la facultad de Odontología y dos departamentos de la Facultad de Ingeniería, pasen a ocupar las instalaciones del Comedor Universitario". Además, "en estos momentos se hallan abocados en el inventario del mismo para su posterior venta a través del Banco Municipal de La Plata". ${ }^{15} \mathrm{Al}$ igual que la supresión del bachillerato nocturno del Colegio Nacional, ${ }^{16}$ se trata de la anulación del foco infeccioso mediante la transformación de su espacio, acto que expresaría, quizás, la instauración de "un nuevo tópico represivo, guiado más por la coerción destructiva y clausuradora". ${ }^{17}$

Esta política obturante se expresa, asimismo, en la regulación del espacio arquitectónico universitario; las múltiples referencias a inscripciones, murales y carteles pegados en las paredes dan cuenta de una concepción de estas como lugares pretendidamente limpios: "en esta oportunidad fué colocado un cartel sin refrendar, en una de las paredes de un pasillo interior de la planta baja", "en una de las paredes de la Facultad de Ciencias Médicas fué pegado un panfleto sin identificación con el siguiente texto", 18 "dichas inscripciones fueron efectuadas con pintura en aerosol color negro, con caracteres variables que van desde 0,50 a $0,70 \mathrm{mts}$ y abarcan extensiones de 4 a 7 mts."," "la inscripción [...] que rezaba 'Trelew ni olvido ni perdón', y 'Educación para mantener al imperialismo', fueron borradas por disposición de las autoridades del citado ente". ${ }^{20}$ El análisis de estas inscripciones en un espacio vigilado le permitirá a las fuerzas armadas reprimir cualquier manifestación o actitud contraria: "Al día siguiente se presentó en la Facultad una patrulla militar la cual sin necesidad de intervenir abortó la intensión [SIC] del alumnado". $\mathrm{La}$ DIPBA ayudará en esta tarea individualizando el origen de las inscripciones mediante su análisis textual y contextual:

14 Lanteri, Magdalena, Kahan, Emmanuel Nicolás, Sahade, Julieta, Iuliano, Rodolfo Martín, Bogliano, Verónica, Balbuena, Yamila, Mannarino, Juan Manuel, González Canosa, Mora, Balut, Pablo, y Bugnone, Ana, "La mirada de la DIPBA (Dirección de Inteligencia de la Policía de la Provincia de Buenos Aires) sobre el movimiento estudiantil platense", en Memoria Académica, p. 18, en línea en: http://www.memoria.fahce.unlp.edu.ar/library? $\mathrm{a}=\mathrm{d} \& \mathrm{c}=$ eventos\&d=Jev6676, consulta: 19 de marzo de 2018.

15 Mesa "A", Legajo 20, Tomo VII, folio 18. Fondo DIPBA.

16 Mesa "A", Legajo 20, Tomo VII, folio 19. Fondo DIPBA.

17 Lanteri, Magdalena, et al., "La mirada de la DIPBA...", op. cit., p. 19. Sin embargo, la política espacial de la dictadura no adquiere sólo el carácter de clausura, sino de conservación y constitución de ciertos monumentos nacionales, como el Museo de Ciencias Naturales o la firma de un convenio entre la Universidad y la Municipalidad de La Plata en la que esta última se comprometía a la "conservación y mantenimiento de los espacios verdes, parques, senderos, paseos, patios externos, etc., que formen parte del patrimonio" de la primera. Ver: Mesa "A", Legajo 20, Tomo VII, folios 19 y 62, respectivamente. Fondo DIPBA.

18 Mesa "A", Legajo 20, Tomo VII, folio 22. Fondo DIPBA.

19 Mesa "A", Legajo 20, Tomo VII, folio 63. Fondo DIPBA.

20 Mesa "A", Legajo 20, Tomo VII, folio 64. Fondo DIPBA.

21 Mesa "A", Legajo 20, Tomo VII, folio 21. Fondo DIPBA. 
"La ausencia de otros indicios solamente permite el análisis del contenido del panfleto y su redacción e impresión, advirtiéndose la carencia de terminología marxista, circunstancia que abre la posibilidad de que se trate de un hecho personal o bien de la tendencia FRANJA MORADA, expresión mayoritaria dentro del actual espectro políticouniversitario". ${ }^{22}$

"La sigla F.U.R. no es conocida en la actualidad como representativa de agrupación política o estudiantil de actuación en este medio, no obstante se tiene conocimiento de un intento del E.R.P. de crear un frente único con la izquierda marxista y revolucionaria, que en el ámbito universitario podría traducirse en la conformación de la citada F.U.R". ${ }^{23}$

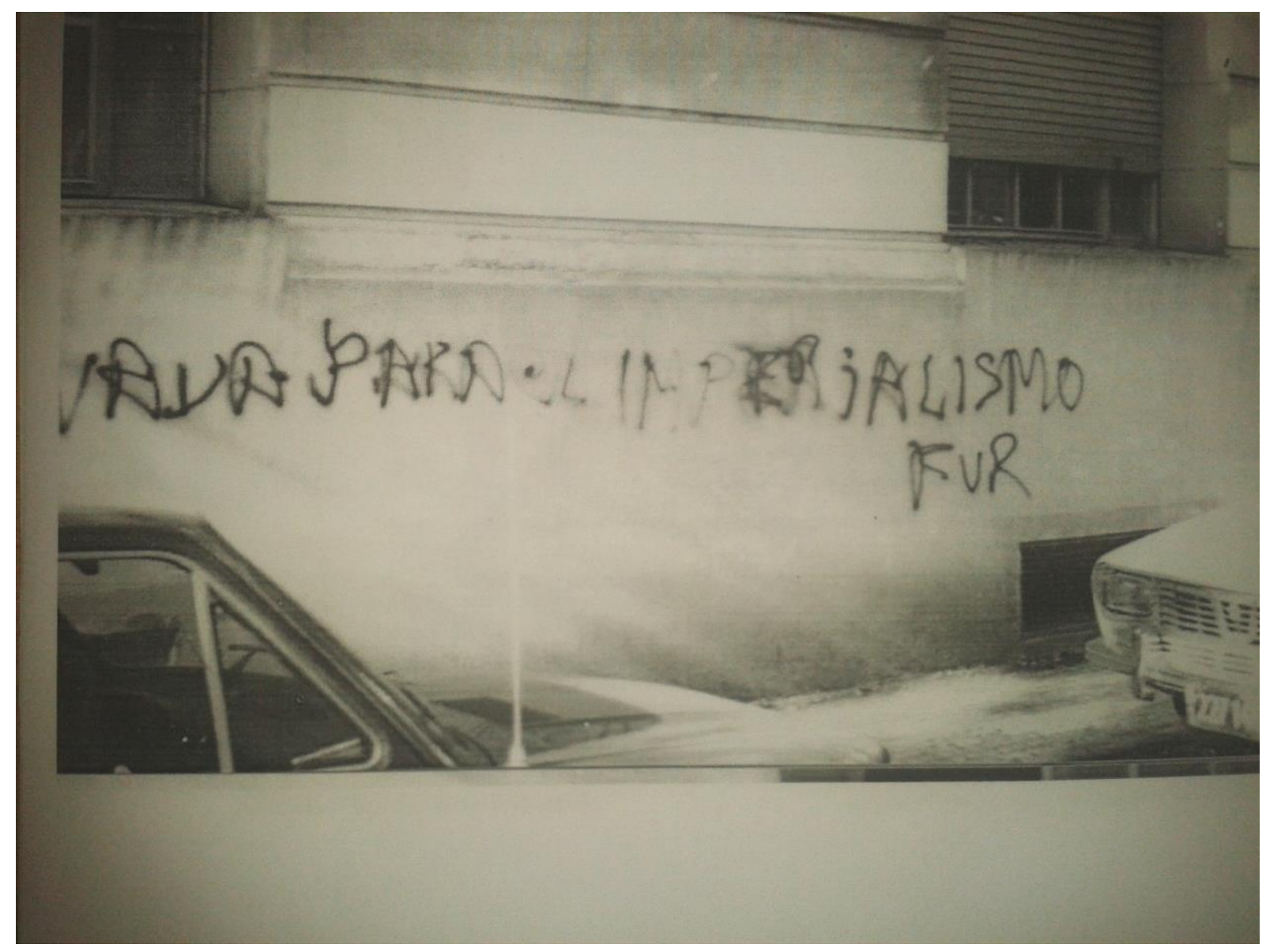

Imagen 1: Fotografía tomada por agente de la DIPBA sobre una inscripción. Extraído de: Mesa “A”, Legajo 20, Tomo VII, folio 68. Fondo DIPBA

La investigación del espacio de la Universidad implica, a su vez, una lectura sistemática del espacio que destaque lo irregular sobre lo normal. La Universidad como espacio físico -esto es, como campus - se inscribe como espacialidad distinguida en el contexto de la morfología de una ciudad como La Plata, con su trazado hipodámico y su estilo cuantitativo en la nominación de calles y avenidas. Ya en un sentido etimológico, el campus (término inglés que proviene del latín, "llanura") contrasta con lo urbano no en cuanto al relieve sino en tanto espacio fértil. La disposición irregular de los edificios universitarios, aun cuando su construcción respeta el modelo de emplazamiento rectangular urbano, autoriza la existencia de lugares, pasajes y pasillos de distinta anchura y longitud, zonas de sombra y puntos ciegos que contrarrestan una vigilancia 
económica. Es en esos puntos donde, de hecho, son colocados y pintados los carteles y las inscripciones murales, tal como muestran los croquis anexos a los informes:

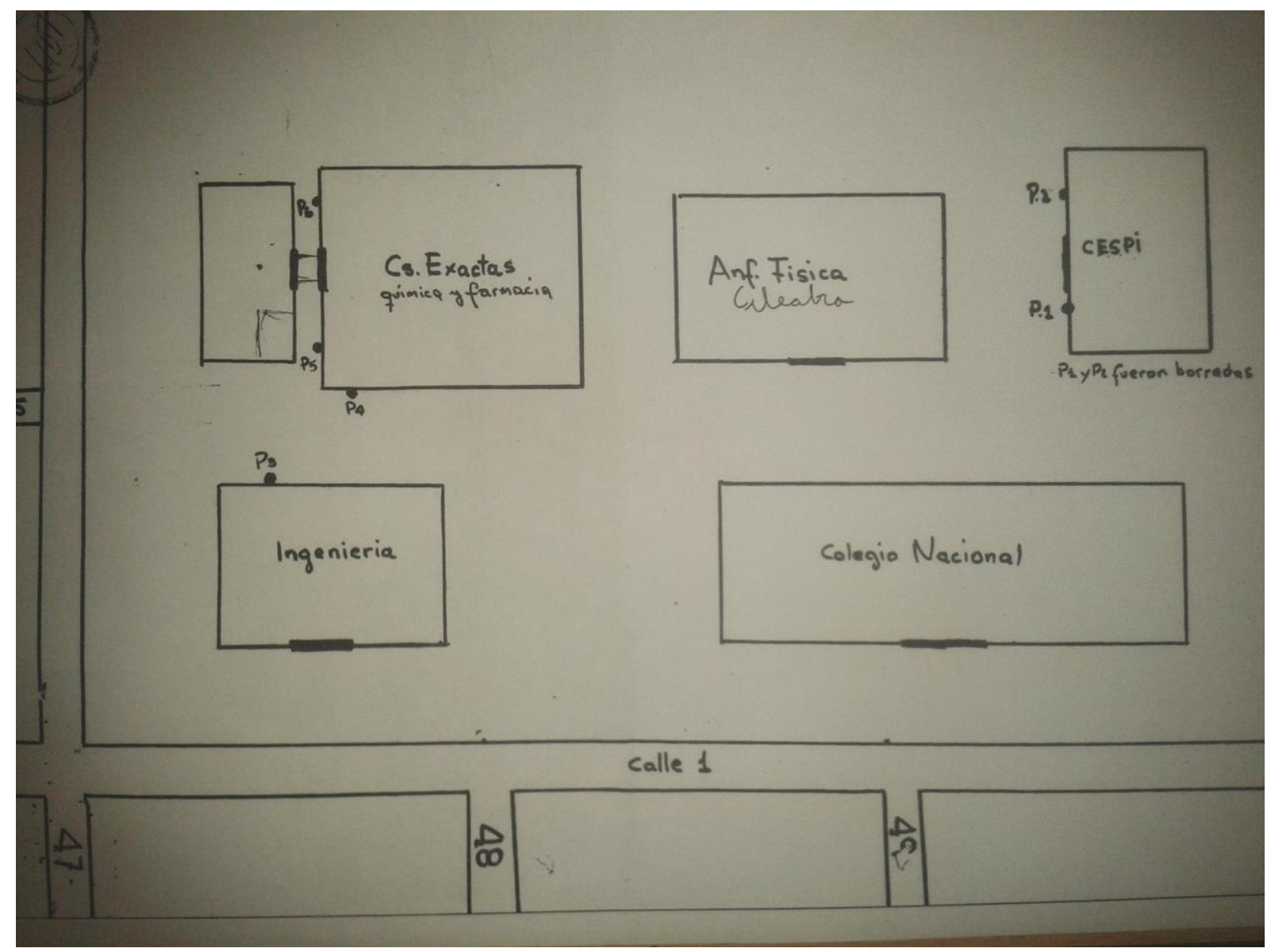

Imagen 2: Croquis que representa el campus universitario. Los puntos señalan las inscripciones murales realizadas por organizaciones clandestinas. Extraído de: Mesa "A", Legajo 20, Tomo VII, folio 65. Fondo DIPBA

Desde mediados de 1977 hasta mediados de 1981 las inscripciones y volantes dejan, en la mayoría de los casos, de ser refrendados por organizaciones políticas. Esto sin duda es consecuencia de las políticas de persecución, tortura y desaparición forzada de personas. El terrorismo era identificado en los reclamos "alrededor del comedor para los estudiantes, las bibliotecas, las actitudes excesivamente rigurosas o exigentes de algún profesor, la autonomía universitaria, el ingreso irrestricto y a favor del gobierno tripartito con participación estudiantil". ${ }^{24}$ En este sentido, quizás sea posible sugerir que, al igual que la anulación de los espacios que son percibidos como focos de contagio del terrorismo, la acción de desaparecer no sería simplemente el ejercicio de un poder de muerte, sino que tendría una dimensión vinculada a la despoblación como anulación de los cuerpos, nombres y espacios, y como modificación de las constantes estadísticas de la población universitaria. En este sentido, la política espacial-poblacional de la dictadura en la Universidad

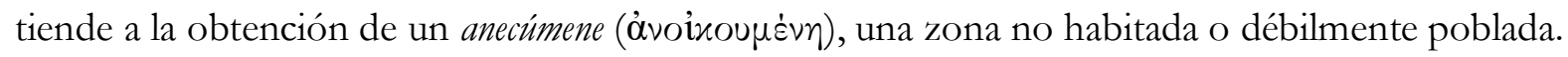

Por su parte, la desaparición tiene un carácter productivo, ya que entraña un extrañamiento del espacio que es en realidad un no-espacio -el campo de concentración, el centro clandestino de detención-, y que a su vez dota de una configuración concreta al gran espacio de seguridad. Este espacio "comporta la radical definición del enemigo como extraño al espacio y a la vida", y "se 
coloca con respecto no a un enemigo externo o interno a las fronteras nacionales, sino a un noespacio que está a la vez dentro y fuera de estas". ${ }^{25}$

\section{El control poblacional}

En la Universidad, la búsqueda de una (des)población óptima no se plasmó únicamente en las políticas de redimensionamiento, sino que se buscó reconvertir de pies a cabeza la comunidad universitaria, eliminando todos los factores reales o potenciales de perturbación.

En primer lugar, el control espacial-poblacional dependió de la colocación de autoridades interventoras de la Universidad, que pudieran materializar los lineamientos del Ministerio de Educación. En una nómina de autoridades encontrada en el $\operatorname{archivo~}^{26}$ es posible observar que todas las dependencias universitarias se encontraban bajo la égida de un decano "normalizador", y lo mismo ocurría con varias de las dependencias no universitarias de la UNLP. También fue común la renuncia de autoridades y decanos debido a "desinteligencias" con el Rector Gallo o "por razones estrictamente personales". 27

El personal docente y no docente podía ser factor de perturbación, sobre todo a raíz de la quita de presupuesto. ${ }^{28}$ Fueron comunes las cesantías ${ }^{29}$ e inhabilitaciones, aunque se menciona también un fallo de 1980 del juez federal Héctor Carlos Adamo, a favor de un profesor que "había sido dado de baja en Marzo del 76, por encontrarlo incurso en lo previsto en el Art $1^{\circ}$ de la Ley 21.274", calificándolo de "factor real o potencial de perturbación del normal desenvolvimiento del organismo". ${ }^{30}$ Dicho juez declaró en el diario La Razón que

"Resulta indudable, a mi criterio -agrega-, que la ley 21.274, dictada en circunstancias muy especiales para la sociedad argentina, no puede interpretarse de manera tal que pueda ser utilizada en forma arbitraria por los funcionarios administrativos en perjuicio de sus agentes, debiendo limitarse la aplicación del artículo 6, inciso 6 [que restringía el derecho de indemnización], en forma restrictiva y para los casos en que, efectivamente, pueda demostrarse esa peligrosidad de que se acusa a los agentes, a quienes se sanciona con tal medida". ${ }^{31}$

Sin embargo, el control más acuciante hizo eje en la población estudiantil. Las políticas de redimensionamiento universitario introdujeron

"la reducción del cupo de estudiantes por carreras, el arancelamiento de diversos trámites administrativos y la supresión o fusión de casas de estudios y carreras. En suma, se trataba de políticas destinadas a recortar el número de universidades y el porcentaje de estudiantes inscriptos". ${ }^{32}$

25 Cavalletti, Andrea, Mitología de la seguridad..., op. cit., p. 258. Al decir de Giorgio Agamben, el campo de concentración será la culminación de aquel proceso en el que la biopolítica se realiza en tanatopolítica. Ver: Agamben, Giorgio, Estado de excepción, Buenos Aires, Adriana Hidalgo, 2014.

26 Mesa "A", Legajo 20, Tomo VII, folios 11 a 17. Fondo DIPBA.

27 Mesa "A", Legajo 20, Tomo VII, folio 54. Fondo DIPBA.

28 Mesa "A", Legajo 20, Tomo VII, folio 18. Fondo DIPBA.

29 Mesa "A", Legajo 20, Tomo VII, folio 4. Fondo DIPBA.

30 Mesa "A", Legajo 20, Tomo VII, folio 48. Fondo DIPBA.

31 La Razón, La Plata, 22 de febrero de 1980, "Otro Profesor Rehabilitado por la Justicia". Mesa "A", Legajo 20, Tomo VII, folio 47. Fondo DIPBA.

32 Rodríguez, Laura Graciela, y Soprano, Germán, "La política universitaria de la dictadura militar en la Argentina: proyectos de reestructuración del sistema de educación superior (1976-1983)", en Nuevo Mundo Mundos Nuevos, en línea en: http://journals.openedition.org/nuevomundo/56023, consulta: 13 de febrero de 2018. 


\section{FACTOR DSTUDIANIII}

\section{INORSS A L:S UNIVIRSTDADIS NATIONALIF:}

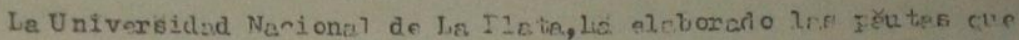

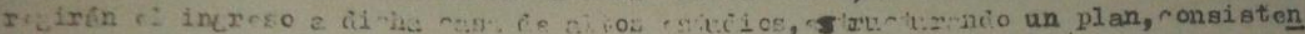

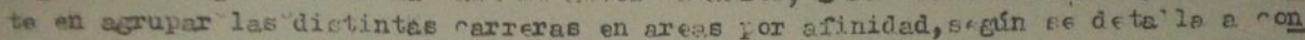

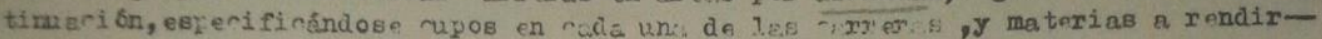
en el ingreso.-

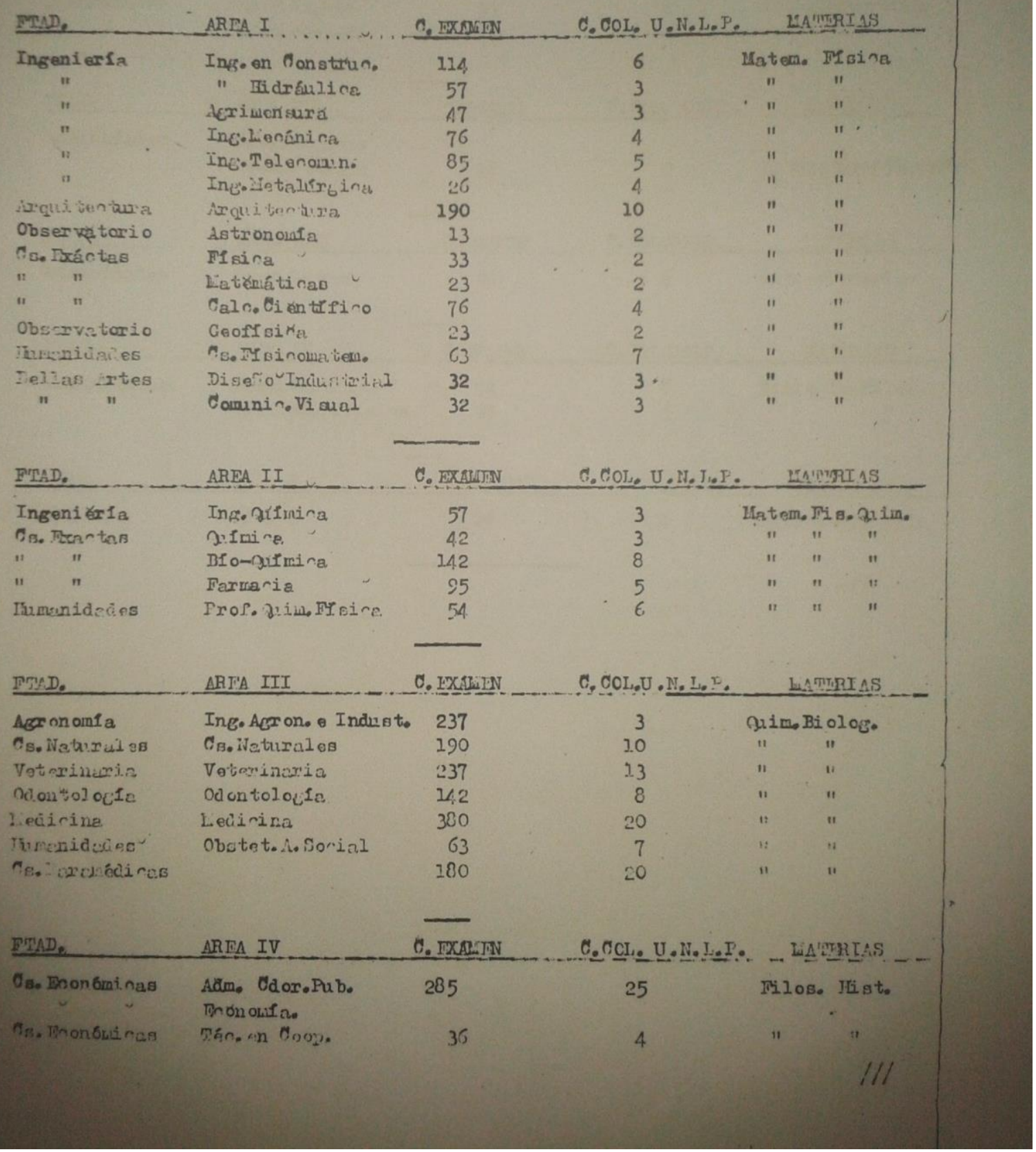

Imagen 3: Tabla que agrupa las distintas carreras por áreas de afinidad. Extraído de: Mesa "A", Legajo 20, Tomo VII, folio 40. Fondo DIPBA 
El redimensionamiento supuso el control del acceso a "las arterias" de la Universidad ${ }^{33}$ y de la concurrencia de los "numerosos" alumnos ${ }^{34}$ mediante un temprano reforzamiento represivo presencia de las Fuerzas Armadas, pedidos de libreta y documentos personales- y, sobre todo, el control del ingreso. Este último implicó, como condiciones, el "desmembramiento" de las "Organizaciones Subversivas", ${ }^{5}$ el "desplazamiento" de "sectores", "núcleos" y "nucleamientos", y la expulsión directa -mediante amenazas como las de la "Agrupación de Derecha Armada Nacional (ADAN)" - o indirecta -por la extrema restricción del cupo- de los estudiantes extranjeros, ${ }^{37}$ lo que permitió el "estricto ordenamiento que hoy ofrecen las Casas de Altos Estudios". ${ }^{38}$ En segundo lugar, implicó la restricción de los cupos en todas las dependencias universitarias.

El control del ingreso es una constante en las producciones agrupadas en estos tomos del Legajo 20. Sin embargo, es en un trabajo realizado por la Delegación de Inteligencia de La Plata sobre los cursos de ingreso de $1979^{39}$ donde se muestra este afán en todo su esplendor estadístico. En este, se despliega la agrupación de carreras por áreas de afinidad, la construcción de tablas estadísticas y comparativas, y la elaboración de propuestas sofisticadas que implican el acrecentamiento de una vigilancia centrada "en los establecimientos de mayor caudal de inscriptos, cuya afluencia puede ser aprovechada para provocar alteraciones del orden". ${ }^{40}$

La búsqueda de una población justa comparte las características de las modalidades de regulación estadística. Cavalletti ha subrayado el carácter teológico-político originario del argumento de las regularidades estadísticas como instauradora de una normalidad, ${ }^{41}$ lo que en nuestro caso también subyace a la búsqueda de una armonía nunca lograda en la relación entre aspirantes y cupos de ingresantes, que a su vez se vuelve tópico problemático:

"No obstante lo expresado, no se descarta que una vez comenzados los referidos cursos, se intente, por parte de las distintas tendencias políticas en el ámbito Universitario, captar nuevos adeptos, dada la inexperiencia de los ingresantes, en su totalidad provenientes de Escuelas Secundarias donde el promedio de edad es aproximadamente de 17 años, circunstancia por la cual las tendencias tratarán de insistir en el hecho que [SIC] los cupos de ingresos son ínfimos, en relación a la cantidad de inscriptos". ${ }^{42}$

El tratamiento poblacional inscripto en el control del ingreso a la Universidad se expresa, también, en la consideración de los estudiantes extranjeros como elemento peligroso ligado a tendencias izquierdistas. En una "información URGENTE" solicitada por el Presidente de facto Jorge Rafael Videla mediante la Dirección de Asuntos Policiales del Ministerio del Interior, se informa que

"Ante el temor de sufrir algún tipo de atentado, alrededor de un centenar de estudiantes de nacionalidad peruana abandonaron el país en la primera quincena de septiembre, trasladándose por vía aérea a Lima (Perú), en tanto que un $80 \%$ de la colonia estudiantil residente en La Plata, decidió no trasladarse al país de origen pese a las amenazas,

33 Mesa "A", Legajo 20, Tomo VII, folio 2. Fondo DIPBA.

34 Mesa "A", Legajo 20, Tomo VII, folio 6. Fondo DIPBA.

35 Mesa "A", Legajo 20, Tomo VII, folio 38. Fondo DIPBA.

36 Mesa "A", Legajo 20, Tomo VII, folio 9. Fondo DIPBA.

37 Mesa "A", Legajo 20, Tomo VII, folios 9 y 10. Fondo DIPBA.

38 Mesa "A", Legajo 20, Tomo VII, folio 38. Fondo DIPBA.

39 Mesa "A", Legajo 20, Tomo VII, folios 36 a 45. Fondo DIPBA.

40 Mesa "A", Legajo 20, Tomo VII, folio 45. Fondo DIPBA.

41 Cf. Cavalletti, Andrea, Mitología de la seguridad..., op. cit.

42 Mesa "A", Legajo 20, Tomo VII, folio 38. Fondo DIPBA. 
permaneciendo en la Argentina. Durante dicha partida, muchos de los mencionados negaron su participación en actividades izquierdistas en ámbitos universitarios". ${ }^{43}$

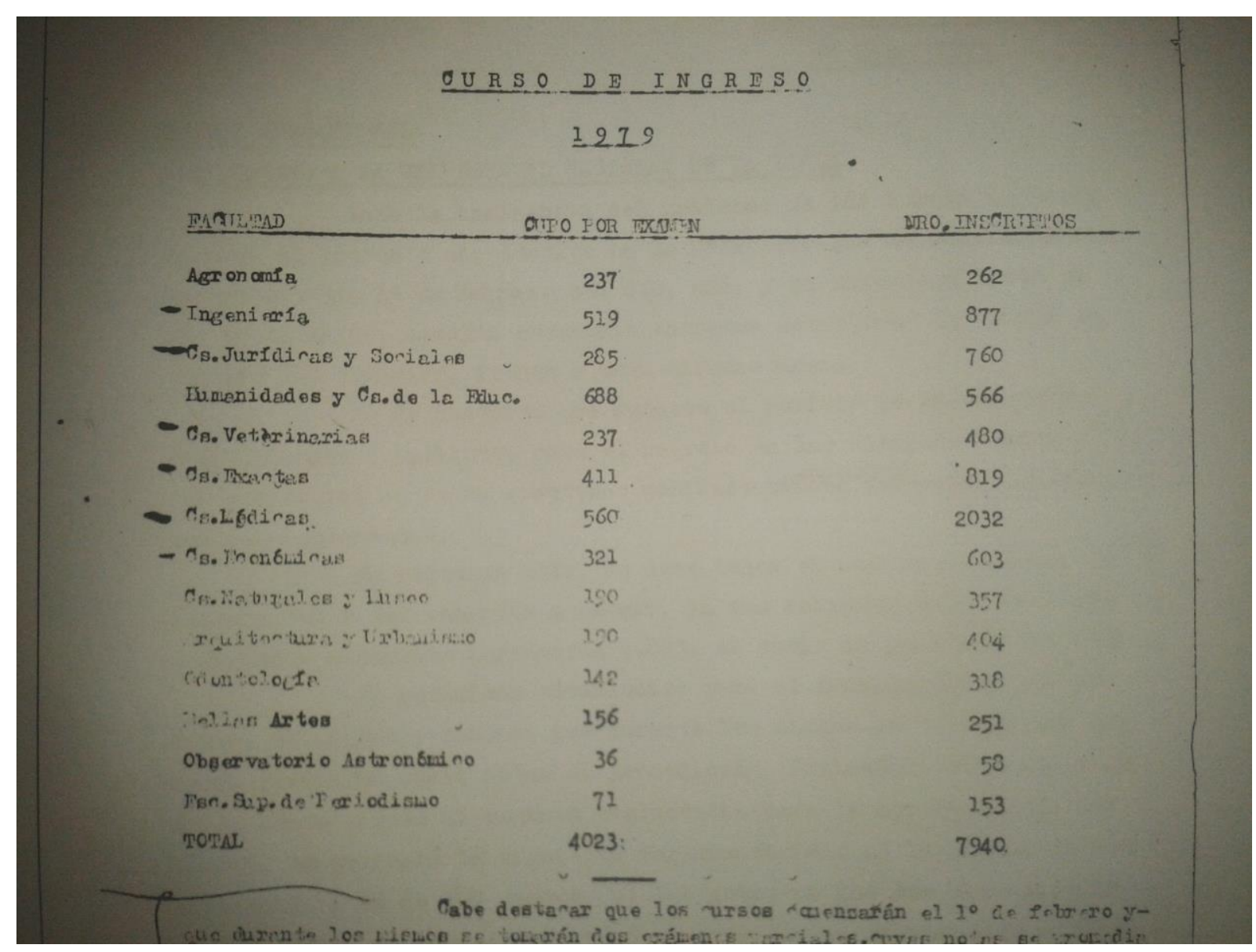

Imagen 4: Tabla de relación entre cupos e inscriptos. Extraído de: Mesa “A”, Legajo 20, Tomo VII, folio 42. Fondo DIPBA

El ingreso de los estudiantes extranjeros fue restringido en 1976 por las autoridades ministeriales, quienes dispusieron que "en la U.N.L.P. podrán hacerlo solamente 111 estudiantes en las diferentes facultades, sobre un total de 7.787 alumnos que podrán ingresar en 1977". ${ }^{44}$

Este empeño general por la desmasificación se basó en el razonamiento político de que el crecimiento de la matrícula universitaria "había alimentado el proceso de radicalización política de estudiantes y profesores, un fenómeno que había terminado instalando la 'subversión' en sus aulas". ${ }^{45}$ Sin embargo, y a pesar de los intentos de una definitiva normalización del sistema con la Ley Universitaria de $1980,{ }^{46}$ la amenaza del resurgimiento de la subversión estaría siempre latente.

43 Mesa "A", Legajo 20, Tomo VII, folio 10. Fondo DIPBA.

44 Mesa "A", Legajo 20, Tomo VII, folio 10. Fondo DIPBA.

45 Rodríguez, Laura Graciela, y Soprano, Germán, "La política universitaria de la dictadura militar...", op. cit.

46 Rodríguez, Laura Graciela, y Soprano, Germán, "Las políticas de acceso a la universidad durante el proceso de reorganización nacional, 1976-1983”, Question, vol. 1, núm. 24, en línea en: http://sedici.unlp.edu.ar/handle/10915/33312, consulta: 14 de febrero de 2018. 


\section{Regulación económico-sanitaria}

El control del ingreso de la población estudiantil se ejerció en paralelo a otras políticas de control poblacional, de trasfondo económico-sanitario. La articulación entre concepciones sobre la seguridad, la salud y la economía, como despliegues dóxicos emergentes en el corpus, indican el carácter biopolítico de este discurso y de estas políticas de control.

La conexión de la seguridad con la salud no sólo se vincula con la proliferación de metáforas médicas en los discursos sobre la criminalidad y el enemigo interno, sino que posee un aspecto genealógico en el sentido de que la policía estuvo históricamente ligada a la expurgación de infecciones. ${ }^{47}$

En nuestro corpus, el aspecto sanitario de las políticas de control universitario se encuentra bien expresado en un informe de fines de 1977 sobre la creación de un "Fondo de Ayuda a la Salud Estudiantil". ${ }^{48}$ En los considerandos, se enuncia el carácter "preventivo-asistencial" del programa, y el fundamento de que "la salud es uno de los pilares básicos y fundamentales de la Nación", para lo cual es necesario "adoptar una política agresiva en salud". La intensificación de las medidas preventivas supone la realización de un "examen médico de ingreso" a docentes, no docentes y estudiantes, y "exámenes periódicos" a estos últimos. La consideración dóxica de la salud la inscribe en un entramado de correlaciones económicas, sociales y etarias, lo que permite construir al "estudiantado" como población con características específicas, dada la evidencia de

"los problemas socio-económicos que presenta el estudiantado y la falta de cobertura asistencial que se advierte en la mayoría de los casos, como consecuencia de la edad promedio de los alumnos, de la falta de asistencia médica por parte de Obras Sociales; que esta situación se ha visto agravada en la última año [SIC], ante el aumento de la morbilidad, en enfermedades de tipo social, como el mal de Chagas, tuberculossis, vené reas etc [SIC]". ${ }^{49}$

Por otro lado, el aspecto económico del control poblacional está implícito en la noción de equilibrio óptimo, como "equilibrio económico indispensable" ${ }^{50}$ de los recursos universitarios. Este eufemismo expresa, en realidad, la disminución del presupuesto universitario y la transferencia de fondos hacia el sector privado, dado que al igual que el arancelamiento, el Fondo de Ayuda referido dependió de "que cada estudiante universitario contribuya con una cuota para solventar los gastos mínimos para desarrollar la acción sanitaria que se pondrá en funcionamiento a través de la Dirección Gral. de Sanidad". ${ }^{11}$ Además, la eficacia de tal recaudación habría dependido de su justa administración, prohibiéndose el destino "total" o "parcial" de la misma "a otros fines $[\ldots]$ que no tengan relación directa con la asistencia médica de los estudiantes". ${ }^{52}$

La noción de equilibrio económico fundamenta las apreciaciones que vinculan, por ejemplo, la baja salarial con las "irregularidades" administrativas y el "malestar" social. En el siguiente fragmento, el uso de la categoría "malestar total" sin marcación gráfica de citación presupone dicho malestar como realidad evidente:

"Se ha tomado conocimiento que [SIC] en las facultades de: Arquitectura, Ciencias Exactas; Ingeniería, Farmacia y Química, de esta ciudad, existe un malestar total entre los docentes, motivado por los anuncios publicados de los aumentos salariales. Desde ayer (3-8), comenzaron a observarse algunas irregularidades, tales como la llegada tarde a los cursos;

47 Cf. Cavalletti, Andrea, Mitología de la seguridad..., op. cit.

48 Mesa "A", Legajo 20, Tomo VII, folios 27 a 29. Fondo DIPBA.

49 Mesa "A", Legajo 20, Tomo VII, folio 29. Fondo DIPBA.

50 Mesa "A", Legajo 20, Tomo VII, folio 28. Fondo DIPBA.

51 Mesa "A", Legajo 20, Tomo VII, folio 28. Fondo DIPBA.

52 Mesa "A", Legajo 20, Tomo VII, folio 27. Fondo DIPBA. 
sin por esto afectar el normal desenvolvimiento diario de las cátedras". ${ }^{53}$

El carácter del presupuesto implica la consideración de la red de aceptabilidad intertextual o dialógica en la que se inscribe el enunciado. ${ }^{54}$ En este caso, la relación entre malestar social y economía es una relación evidente que no se fundamenta. Por su parte, el carácter "total" del malestar contribuye a pensar este vínculo como una correlación en términos poblacionales: aquí, el malestar y la economía actúan a escala estadística, los aumentos salariales son una variable que afecta el comportamiento de los docentes como población aunque "sin por esto afectar el normal desenvolvimiento". De esta forma, la categoría de malestar alerta la potencialidad de irrupción futura de la multitud. Lo mismo se observa, aunque ya en otro contexto, en los folios 58 y 59, informe cuya apreciación manifiesta que "dado lo urticante del tema cuestionado [el arancelamiento universitario], profundizado por la actual coyuntura económica, permite inferir que, aun careciendo de programación y/o gravitación puede obtener un éxito espontáneo, surgido precisamente de esa crítica situación". ${ }^{55}$

\section{La amenaza como mitologema}

Norbert Elias ha señalado que en la sociedad moderna

"la organización monopolista de la violencia física no solamente coacciona al individuo mediante una amenaza inmediata, sino que ejerce una coacción o presión permanentes mediatizadas de muchas maneras y, en gran medida, calculables. [...] Su presencia en la sociedad es, habitualmente, una mera posibilidad, una instancia de control. La coacción real es una coacción que ejerce el individuo sobre sí mismo en razón de su preconocimiento de las consecuencias que puede tener su acción al final de una larga serie de pasos en una secuencia [...] esta organización monopolista obliga a los seres humanos a aceptar una forma más o menos intensa de autodominio". ${ }^{56}$

Retomando a Elias, podríamos decir que uno de los objetivos de las fuerzas represivas en la dictadura fue la reestructuración del autodominio mediante la imposición de una nueva (in) calculabilidad de la coacción física, un corrimiento de la "curva de adaptación". ${ }^{77} \mathrm{El}$ reordenamiento educativo jugó un rol importante dado que, en su justa medida, la instrucción implica mecanismos de coacción que extienden el autodominio y vuelven más económico el control poblacional. Por esta razón, la instrucción era "vital" para el modelo de soberanía dictatorial, de ahí la preocupación de la DIPBA por las "desinteligencias" a nivel ministerial sobre la educación primaria y secundaria ${ }^{58} \mathrm{La}$ transformación de la oferta universitaria y el cambio de los planes de estudio ${ }^{59}$ también se enmarcaron en el objetivo de producir una sociedad distinta en términos estrictamente poblacionales.

Sin embargo, en la concepción del gobierno dictatorial, las universidades nacionales eran un sitio problemático. Su propio carácter, sus "aniversarios" -como el de la Reforma Universitaria- ${ }^{60}$ y su "filiación genuina" en la "libertad de pensamiento" ${ }^{61}$ propiciaban la recreación de los focos

53 Mesa "A", Legajo 20, Tomo VII, folio 18. Fondo DIPBA.

54 Angenot, Marc, "Présupposé, topos, idéologème", Études françaises, vol. 13, núm. 1/2, 1977, Département des littératures de langue française de l'Université de Montréal, pp. 11-34.

55 Mesa "A", Legajo 20, Tomo VII, folio 59. Fondo DIPBA.

56 Elias, Norbert, El proceso de la civilización: investigaciones sociogenéticas y psicogenéticas, México, Fondo de Cultura Económica, 2009, pp. 544-545.

57 Cf. Elias, Norbert, El proceso de la civilización..., op. cit.

58 Mesa "A", Legajo 20, Tomo VII, folio 33. Fondo DIPBA.

59 Mesa "A", Legajo 20, Tomo VII, folios 18 y 19. Fondo DIPBA.

60 Mesa "A", Legajo 20, Tomo VII, folio 7. Fondo DIPBA.

61 Mesa "A", Legajo 20, Tomo VII, folio 50. Fondo DIPBA. 
infecciosos. De esta manera, la amenaza de la subversión será insistentemente recreada, constituyendo un mitologema como eterno retorno de un tema que vuelve a iniciar el dispositivo de inteligencia: "se recomienda acrecentar la vigilancia", "se sugiere acrecentar la vigilancia y mantener especialmente centrada la atención en los establecimientos de mayor caudal de inscriptos". ${ }^{63}$

En 1979, en un ambiente normalizado, el foco de la DIPBA en el control del ingreso a la universidad subraya la reunión de tres factores: un elemento de contagio -los partidos y sus "colaterales" como modelo arquetípico de la amenaza-, una víctima no inmunizada -los estudiantes secundarios cuya "inexperiencia" ${ }^{64}$ los hace especialmente pasibles de ser "captados"y el acceso a un espacio dificultosamente purificado. El quid o razón atribuida al posible contagio es un problema poblacional o económico: "el número de inscriptos supera con exceso a las vacantes asignadas". Por lo tanto, "esta Delegación ha elaborado el presente trabajo, teniendo en cuenta posibles implicancias". ${ }^{5}$ El exceso de inscriptos implica una "afluencia" numerosa, que "puede ser aprovechada para provocar alteraciones del orden".

De hecho, aunque ciertas organizaciones hayan sido "anuladas", siempre existe la posibilidad de que aquellas que "mantienen su estructura" intenten recrear un "clima de agitación", aprovechando la confusión que genera el exceso de afluentes:

"De inteligencia realizada, se ha podido establecer que elementos del Partido Socialista de los Trabajadores P.S.T., han recibido directivas de dicho partido sobre las acciones a seguir en el ámbito de la Universidad Nacional de La Plata como ser: inscribirse en los cursos de ingreso, captación de nuevos elementos, promover la agitación, solicitando mayor cantidad de cupos en cada facultad. Igualmente y teniéndose en cuenta que organizaciones estudiantiles tales como la "Juventud Guevarista"; "Juventud Universitaria Peronista"; han resultado anuladas, pero en cambio la "FEDERACION JUVENIL COMUNISTA" (F..C.), actualmente mantiene su estructura; es por ello que se considera que miembros del "P.S.T." y de la "F.J.C.", aprovechando estas circunstancias, se dispondrán a captar nuevos elementos y crear un clima de agitación, ante la falta de las organizaciones citadas en primer término". 66

Aparte del exceso poblacional, otra de las condiciones para la generación de este clima de agitación es la "formación de grupos estables" en las facultades. Sin embargo, la emergencia discursiva de esta condición obedece a la recreación de la amenaza, que siempre es anticipada:

"Si bien [...] hasta el momento no se han detectado manifestaciones o actitudes contrarias al sistema de ingreso establecido, esto obedece a que durante la inscripción no se han dado las condiciones para la formación de grupos estables en las distintas dependencias, situación que sí se concretará al concurrir a las clases, lo que tradicionalmente es capitalizado por las distintas tendencias políticas que actúan en el ámbito universitario, con el fin de captar nuevos adeptos, aprovechando la inexperiencia de los jóvenes cuya edad promedio oscila en los 17 años". ${ }^{67}$

Otra de las prefiguraciones que construyen discursivamente el comportamiento de la amenaza -y que incidirá en los enunciados sobre "el terrorismo" del Poder Ejecutivo Nacional- se relaciona con las técnicas de captación de los elementos subversivos:

62 Mesa "A", Legajo 20, Tomo VII, folio 39. Fondo DIPBA.

63 Mesa "A", Legajo 20, Tomo VII, folios 44 y 45. Fondo DIPBA.

64 Mesa "A", Legajo 20, Tomo VII, folio 38. Fondo DIPBA.

65 Mesa "A", Legajo 20, Tomo VII, folio 37. Fondo DIPBA.

66 Mesa "A", Legajo 20, Tomo VII, folio 39. Fondo DIPBA.

67 Mesa "A", Legajo 20, Tomo VII, folios 43 y 44. Fondo DIPBA. 
"las agrupaciones mencionadas tratarán de insistir, como tema de agitación, en el hecho que [SIC] los cupos de ingresos establecidos son ínfimos en relación a la cantidad de inscriptos, siendo probable que utilicen como medio inicial para la estrategia de sus actividades de captación, la efectivización de volanteadas en forma encubierta, para luego proseguir su tarea, con la formación de comisiones de apoyo a los cursos, charlas de acción sicológica y luego el tratamiento directo de los problemas existentes, tanto a nivel individual como colectivo". ${ }^{68}$

En esta descripción hay implícita una desmitificación -como refutación argumentativa- ${ }^{69}$ del significado de cualquier grupo estudiantil estable. De hecho, tanto las comisiones de apoyo como las cooperativas son consideradas una pantalla de las organizaciones prohibidas:

"En la actualidad por estar prohibida la actividad de los Centros de Estudiantiles, encubre su actividad a través de la "Cooperativa de la Facultad de Medicina", lugar desde donde se generan los movimientos de oposición que se registran en esta casa de estudios". ${ }^{70}$

Por otra parte, está latente la reactivación de los elementos contagiosos, dado que "si bien organizaciones tales como Juventud Guevarista, Juventud Universitaria Peronista, han resultado anuladas en su actual accionar en el medio, no se descarta la posibilidad de un posible resurgimiento de las mismas". ${ }^{71}$ De ahí que se hace necesaria la identificación de los activistas ingresantes, como modo de mantener (literalmente) a raya la subversión:

"En lo que hace al ingreso de activistas, se pudo determinar, que XXXXX, nacido el 18-21953, L.E. XXXXX y con domicilio en la calle XXXXX de esta ciudad, se encuentra registrado en la Facultad de Agronomía, como responsable de la agrupación subversiva P.C.R". ${ }^{72}$

En el fondo, existe algo así como una concepción de la Universidad como espacio de oscura fertilidad. La Universidad es el campus, locus de regeneración de la vida anulada, que señala la necesidad de un control mantenido, y que muestra la imposible incoexistencia de la norma con lo prohibido.

\section{La irrupción de la multitud}

1981 fue un año complejo para las pretensiones de reordenamiento universitario del gobierno militar. A mediados de ese año, en el contexto de una crisis económica en ciernes, aumentaron las críticas a las políticas de arancelamiento y al régimen universitario, en forma de panfletos e inscripciones. Si bien "la actual coyuntura económica, permite inferir que, aún careciendo de programación y/o gravitación puede obtener un éxito espontáneo, surgido precisamente de esa crítica situación", ${ }^{73}$ para la DIPBA la ausencia de concentraciones y movilizaciones indicó, en un primer momento, "el 'fracaso' de la campaña de agitación iniciada con el tema del arancelamiento", "la carencia de apoyo masivo del estudiantado", ${ }^{74}$ y "la carencia de relevancia"75 de las agrupaciones que refrendaban los panfletos y las inscripciones murales.

Sin embargo, hacia fines de 1981 encontramos en nuestro legajo referencias a concentraciones efectivamente realizadas. La concentración es un objeto discursivo que en la DIPBA refiere a la

68 Mesa "A", Legajo 20, Tomo VII, folio 44. Fondo DIPBA.

69 Angenot, Marc, La parole pamphlétaire: contribution à la typologie des discours modernes, París, Payot, 1982.

70 Mesa "A", Legajo 20, Tomo VII, folio 26. Fondo DIPBA.

71 Mesa "A", Legajo 20, Tomo VII, folio 44. Fondo DIPBA. Nótese la redundancia, marcada en cursivas.

72 Mesa "A", Legajo 20, Tomo VII, folio 46. Fondo DIPBA.

73 Mesa "A", Legajo 20, Tomo VII, folio 59. Fondo DIPBA.

74 Mesa "A", Legajo 20, Tomo VII, folio 63. Fondo DIPBA.

75 Mesa "A", Legajo 20, Tomo VII, folio 73. Fondo DIPBA. 
irrupción de la multitud. El carácter de la misma va a depender, sobre todo, del posicionamiento político y discursivo del enunciador, pero en cualquier caso la multitud no deja de contener elementos heterogéneos.

La caracterización intradiscursiva de la concentración va a definir su composición y peligrosidad. La lógica subyacente de esta operación obedece a la individualización de los reales factores de perturbación. La noción de éxito espontáneo, o en otras palabras, la relación evidente y aceptable entre crisis económica y agitación social, niega a las masas -el genérico estudiantado- cualquier tipo de organización política autónoma. Son los grupos "reducidos", las "organizaciones subversivas", y algunos activistas específicos, los que representan el peligro de catalización de la multitud en multitud organizada.

"Llevo a conocimiento del señor Director General, que tal y como estaba previsto, se llevó a cabo en la fecha y frente a los jardines del rectorado de la U.N.L.P., una concentración de aproximadamente 150 personas, entre transeúntes y curiosos y miembros del Movimiento de Orientación Reformista; entre éstos se pudo individualizar a XXXX, estudiante de la Facultad de Humanidades de dicha casa de altos estudios, a la integrante de las denominadas Madres de Plaza de Mayo XXXX". ${ }^{76}$

Esta concentración agrupa al menos tres conjuntos de individuos. La noción de transeúnte implica un desinterés por los motivos de la concentración; lo que lo caracteriza es una postura separada de la concentración y una circulación que es radicalmente heterogénea respecto de las intenciones que la fundamentan. Por su parte, el curioso, categoría más ambigua que la de transeínte, mantiene una postura separada de los motivos políticos de la concentración, pero comparte una unidad de movimiento con la misma; ya no se trata de una circulación sino de un acercamiento simpático al mero hecho de concentrarse. Por último, están los responsables políticos de la concentración, ya correctamente "individualizados".

El carácter de la concentración implica tanto una ambigüedad en sentido espacial-poblacional como una disputa política, que se desenvuelve también a nivel interdiscursivo dada la inscripción de las producciones de la DIPBA en un heterogéneo conjunto de documentos, panfletos y declaraciones orales. En 1981, para ciertas organizaciones, la concentración oscila entre la realidad de la multitud disuelta ("El jueves 22 una concentración de más de 300 compañeros fue disuelta por la policía") y la necesidad de una multitud masiva y organizada ("¿Cómo cohesionar esas fuerzas? ¿Cómo sumar nuestros reclamos? ¿Cómo hacer que este repudio se convierta en una gran concentración de masas contra el arancel?"). La ambigüedad de la concentración remite al carácter anfibológico de la noción de multitud, que oscila entre un polo positivo y otro negativo, los cuales se encuentran confundidos en la concentración por la acción presuntamente perturbadora de las organizaciones políticas. La disputa, que evidencia el carácter de signo ideológico ${ }^{77}$ de la voz concentración, radica en la pretensión de legitimidad del uso de la violencia contra la misma, versus la pretensión de recuperar la Universidad, y la misma ciudad-cuyo primer signo son las "marchas callejeras"-:

"Las marchas callejeras en Rosario, Córdoba y Capital son un reflejo de la voluntad del estudiantado universitario por ponerse en pié de lucha contra la arancelización. En casi todas las universidades y facultades del país se va generalizando la necesidad de reconstruir los centros y federaciones para recuperar nuestras conquistas avasalladas por la dictadura militar. Nuestra ciudad no es ajena a este importante reanimamiento que recorre las filas del movimiento estudiantil". ${ }^{78}$

76 Mesa "A", Legajo 20, Tomo VII, folio 79. Fondo DIPBA.

77 Voloshinov, Valentin Nikolaevich, El signo ideológico y la filosofía del lenguaje, Buenos Aires, Nueva Visión, 1976.

78 Volante firmado por la Unión de Juventudes por el Socialismo, Mesa "A", Legajo 20, Tomo VII, folio 80. Fondo DIPBA. 
Progresivamente, la irrupción de la multitud hará retroceder a las fuerzas represivas, de la prohibición inicial a "una discreta vigilancia”, relación que se cristalizará en 1983.

"La concentración, que había sido prohibida por la policía [...], comenzó sin inconvenientes luego de haber cantado el Himno Nacional y entonado diversos estribillos.

En las proximidades del Rectorado, en 7 entre 47 y 48, pleno centro de esta ciudad, se registraba una discreta vigilancia policial". ${ }^{79}$

\section{Consideración final. La (in)seguridad como supervivencia}

La política espacial-poblacional del gobierno militar en la Universidad Nacional de La Plata fue una política de despoblación y desmasificación que, propongo, tendió a la obtención de un anecúmene, una zona deshabitada o escasamente poblada. El interior de esta zona entrañó espacios vacíos y clausurados, que simbolizaron el traslado de la no-población -los detenidosdesaparecidos- a un no-espacio -el centro clandestino de detención-, como forma de anulación de la amenaza. La población que restó y que sobrevivió en la Universidad fue gestionada a nivel político y económico-sanitario, y a partir de la clausura de los focos infecciosos y el control del ingreso se intentó mantener a la Universidad en un relativo estado de pureza.

Sin embargo, para la DIPBA la amenaza continuó latente, constituyendo un mitologema que permitía iniciar, una y otra vez, el dispositivo de seguridad. La supervivencia de la amenaza en la Universidad quizás responde a una concepción de la oscura fertilidad del campus, como espacio de generación y recreación de ciertas formas de vida prohibidas. Es la irregularidad espacial de la ciudad universitaria la que inhibe la vigilancia absoluta, permitiendo la aparición de inscripciones murales, carteles y panfletos durante el período de represión más intenso (1976-1981).

Esta recreación mitologemática de la amenaza, como polo poblacional de intensidad negativa, se vincula de forma ambigua a la irrupción de la multitud, cuyo carácter en el período 1981-1983 oscila entre la multitud disuelta (objeto de gobierno y de regulación biopolítica) y la multitud organizada (sujeto de gobierno, pero también, símbolo de decadencia u objeto de repulsión). ${ }^{80}$ De esta manera, la noción de multitud, desdoblada y reconfigurada en las nociones modernas de pueblo y población, ${ }^{81}$ encierra también una disputa política, que puede observarse en el contraste entre los informes de la DIPBA -fundados en la prohibición y disolución de la multitud-y las producciones anexas de las organizaciones políticas -que buscaban su irrupción masiva-. Si una parte deseaba disolver la concentración de modo presuntamente legítimo, la otra buscó la recuperación de la ciudad y de las calles por la multitud. En algún momento, entre 1981 y 1983 , las relaciones de fuerza entre las fuerzas represivas y la multitud en proceso de organización se jugaron en un espacio de indecidibilidad ${ }^{82}$ entre un objetivo y otro. Esta contienda también se desarrolló en la Universidad Nacional de La Plata. En esta zona de anomia confluyeron, tal vez, una violencia mítica sin ley, pero que pretendía actuar con "fuerza de ley", 83 y la prefiguración de "una violencia pura inmediata" que quiso "detener el curso de la violencia mítica". ${ }^{84}$

Por otra parte, la anulación y la latencia, como estado doble de la amenaza, parecieron definir el

79 Mesa "A", Legajo 20, Tomo VII, folio 81. Fondo DIPBA.

80 Cf., por ejemplo, Le Bon, Gustave, Psicología de las multitudes, Madrid, Daniel Jorro, 1911.

81 La ambigüedad y confusión de las nociones de pueblo y población, que en español comparten una misma raíz léxica y origen, es claramente señalada en el siguiente lema del Frente Peronista Universitario: "SOLO EL PUEBLO SALVARÁ AL PUEBLO”. Mesa "A”, Legajo 20, Tomo VII, folio 101. Fondo DIPBA.

82 La noción de espacio de indecidibilidad es tomada de la obra de Agamben, donde refiere al borramiento de los límites entre regla y estado de excepción.

83 Agamben, Giorgio, Estado de excepción, op. cit.

84 Benjamin, Walter, Crítica de la violencia, Madrid, Biblioteca Nueva, 2010, p. 114. 
ambiguo carácter de la supervivencia en la Universidad. Si por un lado la seguridad estuvo definida como la supervivencia a lo que ya fue anulado, la latencia y la opaca fertilidad del espacio universitario habrían sugerido la misma supervivencia de la amenaza. Seguridad e inseguridad estuvieron definidas como sensaciones inmanentes a la misma acción de sobrevivir. Durante el período que va de 1976 a 1981, las inscripciones murales sobre las desapariciones indicaron, para la DIPBA, esta dual existencia de la amenaza:

"Exigimos la reaparición de: Luis Dimatia (Medicina); Néstor Zaragoza (Medicina); José Juan Riquesa (Geología); José Luis Suarez (Educación Física); Ana Diego (Ciencias Exactas) y María Isabel Navarrete (Medicina) secuestrados en sus domicilios por policías uniformados y de civil el 9 del corriente (los 4 primeros) todos afiliados al Partido Comunista Argentino. Si querés la paz defiende la vida". ${ }^{85}$

"Que aparezcan los estudiantes Robustelli; Sotto y Ebear secuestrados por los milicos". 86

"Exigimos la pronta reaparición de los compañeros Gamallo y Paladino que fueron detenidos sin causa ni motivo alguno. Los estudiantes debemos estar unidos para alcanzar la paz y felicidad que todos los argentinos anhelamos". ${ }^{87}$

85 Mesa "A", Legajo 20, Tomo VII, folios 22 y 23. Fondo DIPBA.

86 Mesa "A", Legajo 20, Tomo VII, folio 23. Fondo DIPBA.

87 Mesa "A", Legajo 20, Tomo VII, folio 22. Fondo DIPBA. 